\title{
Alkali-Activated Concrete: Engineering Properties and Stress-Strain Behavior
}

\author{
Robert J. Thomas, Sulapha Peethamparan* \\ Department of Civil and Environmental Engineering, Clarkson University, Potsdam, NY \\ 13699, USA
}

\begin{abstract}
This paper presents an investigation into the tensile strength, modulus of elasticity, Poisson's ratio, and stress-strain relationships of alkali-activated portland-cement-free concrete made with fly ash or ground granulated blast furnace slag (GGBFS) as the sole binder. Alkali-activated concrete is shown to be stronger in tension and have lower Poisson's ratio than portland cement concrete. Relationships are proposed to estimate the tensile strength and modulus of elasticity based on the compressive strength of alkali-activated concrete, which are of the same form as those currently employed for portland cement concrete.
\end{abstract}

Keywords: Alkali-activated concrete, modulus of elasticity, Poisson's ratio, stress-strain curve, tensile strength

\footnotetext{
*Corresponding author Tel: +1-315-268-4435

Email addresses: thomasrj@clarkson.edu (Robert J. Thomas), speetham@clarkson.edu (Sulapha Peethamparan )
} 


\section{Introduction}

Portland cement concrete (PCC) is the most widely used construction material, with production reaching one hundred million tonnes in the United States in 2005 [1, 2]. Even as domestic production declines, global consumption of portland cement grows significantly. Modern advancements to the portland cement manufacturing process have reduced associated energy consumption and emissions, but even the most modern operations use as much as 4 GJ of energy and emit nearly one tonne of carbon dioxide per tonne of cement produced [3-6]. This is by no means a new revelation; the concrete industry has long sought means to supplement or replace portland cement in concrete. Partial cement replacement with cementitious or pozzolanic industrial wastes like fly ashes and ground granulated blast furnace slag (GGBFS) has been employed with measurable success. These modifications not only improve the sustainability of concrete, but have also been shown to improve rheology, mechanical strength, and durability [7-10]. As an added benefit, repurposing industrial wastes reduces landfilling costs and associated environmental impact. Despite numerous and well-established benefits of partial cement replacement, fly ash and other pozzolans are typically limited to about $25 \%$ of total cementitious material, while GGBFS is often used in quantities as high as $50 \%$ of total cementitious material. A few studies have investigated the feasibility of high-volume cement replacement with some success, but these mixtures still require the use of a significant amount of portland cement $[11,12]$.

More recently, a number of studies have demonstrated the synthesis of portland cement-free binders by alkali activation of industrial byproducts and 
natural pozzolans. Turner and Collins [13] recently suggested that alkaliactivated binders can result in as much as $45 \%$ reduction in total carbon emissions associated with concrete production. The activation of GGBFS, fly ashes, and natural pozzolans with sodium and potassium alkalis has been shown by several studies to result in strong and durable binders [14-19]. Arguably the most common and effective activator used in relevant studies is sodium silicate, i.e., $\mathrm{Na}_{2} \mathrm{O}+m \cdot \mathrm{SiO}_{2}$ where $m$ is the silica modulus. Sodium silicate-activated fly ash and slag concretes have been shown to develop compressive strengths in excess of $30 \mathrm{MPa}$. Some formulations, particularly those based on fly ashes, require elevated temperature curing to develop appreciable early-age strength [20-26]. Although the literature is somewhat conflicted with regard to durability, most available studies have shown activated concrete to exhibit increased resistance to chloride penetration [20, 27, 28], acid attack [29-31], and sulfate attack [32], and reduced potential for deleterious alkali-silica reaction [33-35]. Despite the wealth of knowledge regarding the performance of alkali-activated concrete, very few studies have addressed the engineering properties of activated concrete, viz. the modulus of elasticity, Poisson's ratio, tensile strength, and stress-strain relationships. Thorough understanding of these properties is essential to fully characterize the performance of alkali-activated concrete for the purpose of design and field implementation.

The engineering properties of PCC are generally well understood. The tensile strength $f_{c t}$, measured by the splitting tension (Brazilian) test, is typically $10-15 \%$ of the compressive strength $f_{c}^{\prime}$. A number of more specific estimates have been proposed which have generally been of the form of Eq. 1, 


$$
\begin{gathered}
f_{c t}=A\left(f_{c}^{\prime}\right)^{B} \\
f_{c t}=0.56 \sqrt{f_{c}^{\prime}} \\
f_{c t}=0.59 \sqrt{f_{c}^{\prime}}
\end{gathered}
$$

59 Young's modulus of elasticity $E(\mathrm{MPa})$ of portland cement concrete is 60 generally estimated as a function of the compressive strength $f_{c}^{\prime}(\mathrm{MPa})$ and the unit weight $w_{c}\left(\mathrm{~kg} / \mathrm{m}^{3}\right)$ as in equation 4, after Pauw [46] and ACI building code 318 [42]. For normalweight concrete this reduces to equation 5 which, it should be noted, is of the same form as equation 1 with $B=\frac{1}{2}$.

$$
\begin{gathered}
E=0.043 w_{c}^{3 / 2}\left(f_{c}^{\prime}\right)^{1 / 2} \\
E=4700\left(f_{c}^{\prime}\right)^{1 / 2}
\end{gathered}
$$



(Equation 6-8).

$$
\begin{gathered}
\sigma=\sigma_{0} \frac{\epsilon}{\epsilon_{0}} \frac{n}{n-1+\frac{\epsilon}{\epsilon_{0}}}{ }^{n} \\
\epsilon_{0}=2.7 \times 10^{-4} \sigma_{0}^{\frac{1}{4}} \\
n=0.4 \times 10^{-3} \sigma_{0}+1
\end{gathered}
$$

77 A few studies have discussed the tensile strength of alkali-activated and atively well understood, and is marked by nearly perfect linear elasticity up to the ultimate strength, followed by distinct strain softening $[47,48]$. As the compressive strength increases, so does the brittleness; this manifests as an increasingly steep softening curve. Very high strength concrete exhibits highly brittle failure, with little or no softening behavior prior to complete rupture. Several authors have proposed analytical relationships to describe the stress-strain curve of portland cement concrete, although these relationships tend to be highly dependent on test conditions [49-51]. A reliable numerical stress-strain relationship was determined by Popovics [48] in 1973, wherein the stress $\sigma$ (psi) at a given strain $\epsilon$ is estimated by a function of the ultimate stress $\sigma_{0}$ (psi), the corresponding strain $\epsilon_{0}$, and a constant $n$ geopolymer concrete $[22,44,45,52,53]$. Several have suggested, based on somewhat limited data and without any proposed mathematical relationship, that alkali-activated concrete exhibits improved tensile strength over that typical of portland cement concrete [18, 22, 52, 53]. Specifically, Duran Atiş et al. [53] investigated the mechanical properties of alkali-activated 
GGBFS mortar, concluding that sodium silicate-activated GGBFS mortar exhibited the best tensile strength, and that optimum solution parameters (i.e. silica modulus $m$ and sodium oxide content) exist that provide the best tensile strength performance. A few other studies have shown contradicting results. Lee and Lee [44] found that the tensile strength of concrete made with alkali-activated fly ash/GGBFS mixtures was about 20\% lower than that of portland cement concrete. Similarly, Sofi et al. [45] found that the tensile strength of high-compressive-strength geopolymer concrete made with fly ash and GGBFS was significantly lower than that of both normal and high strength portland cement concrete. The latter two studies proposed two very similar mathematical models to relate splitting tensile strength $f_{c t}$ to compressive strength $f_{c}^{\prime}$, which are given as Equations 9 [44] and 10 [45].

$$
\begin{aligned}
& f_{c t}=0.45 \sqrt{f_{c}^{\prime}} \\
& f_{c t}=0.48 \sqrt{f_{c}^{\prime}}
\end{aligned}
$$

Several authors have reported the modulus of elasticity of various types of alkali-activated concrete in conjunction with other studies, but few have offered any substantial analysis or discussion of significant factors or their effects. These studies have all reported moduli of elasticity in the range of 30-40 GPa [14, 18, 22] for activated fly ash and GGBFS concrete, which is in the same range as expected for portland cement concrete. Based on the results from experiments on alkali-activated natural geopolymer concrete, Duxson et al. [54] suggested that the modulus of elasticity of alkali-activated natural geopolymer concrete is strength-independent, at least within the 
normal range of compressive strengths for structural concrete. Instead, it is suggested that the microstructural development has a more significant effect on the modulus of elasticity, which may be more or less the same for some alkali-activated binders [54]. Lee and Lee [44] proposed the relationship shown in Equation 11 for the modulus of elasticityalkali-activated fly ash/GGBFS mixtures, finding that the ACI equation (Euation 4 overestimated the modulus of elasticity. Poisson's ratio has gone almost entirely unmentioned in conjunction with alkali-activated concrete in available literature, with the exception of Sofi et al. [45], who found Poisson's ratios in the range of 0.24 to 0.26 for inorganic polymer concretes.

$$
E=5300\left(f_{c}^{\prime}\right)^{\frac{1}{3}}
$$

This study seeks to address the aforementioned gaps in knowledge and to cultivate a more thorough understanding of the engineering properties and stress-strain behavior of alkali-activated concrete for the purpose of design and field implementation. Specifically, this study evaluates the compressive strength, splitting tensile strength, modulus of elasticity, Poisson's ratio, and stress-strain response for alkali-activated class-C fly ash (FC) and GGBFS concrete; the results from this study are compared to the typical behavior of portland cement concrete (PCC). Additionally, this study evaluates the efficacy of using existing models for PCC to predict the behavior of alkaliactivated FC and GGBFS concrete. Finally, improved models are proposed to predict the splitting tensile strength and modulus of elasticity of alkaliactivated concretes.It should be noted that the models presented herein relate the splitting tensile strength and modulus of elasticity of alkali-activated con- 
crete to the compressive strength, as is typical for cementitious composites. Since the strong dependence of compressive strength of alkali-activated concrete on the binder, activator, and curing condition have previously been established, the authors do not purport to address the effect of these mixture parameters on the engineering properties of alkali-activated concrete. That is to say, the aim of this paper is to propose relationships with which engineers can easily estimate the engineering properties of alkali-activated concrete without any detailed knowledge of the complex chemical makeup of alkali-activated formulations.

\section{Research Significance}

Although a wide body of literature is available describing the hydration products, reaction kinetics, mechanical strength, and durability of alkaliactivated concrete, the engineering properties, viz., tensile strength, modulus of elasticity, and Poisson's ratio, have received only cursory attention, if any at all. Several papers have specifically called for additional investigations into these areas $[44,53]$. Additionally, the authors are unaware of any studies that have investigated the stress-strain relationships of activated concrete. A complete understanding of these properties and how they relate to one another is vital for design and field implementation of alkali-activated concrete structures. 


\section{Experimental investigation}

\subsection{Materials}

The binder materials used in this study were high-calcium ASTM C618 Class C coal fly ash (FC) and ASTM C989 Grade 100 granulated blast furnace slag (GGBFS), both from reputable commercial suppliers. The oxide composition, as determined by X-ray fluorescence spectrometry, and selected physiochemical properties of the as-received binders are listed in Table 1. The hydration products, reaction kinetics, and mechanical strengths of these binders have bene described by Deir et al. [19] and Gebregziabiher et al. [26]. The activator was a mixed solution of sodium silicate $\left(\mathrm{Na}_{2} \mathrm{O}+m \cdot \mathrm{SiO}_{2}\right)$ and sodium hydroxide $(\mathrm{NaOH})$. The $\mathrm{Na}_{2} \mathrm{O}$ equivalent of the activator is reported relative to binder mass $\left(\% \mathrm{Na}_{2} \mathrm{O}\right.$, by mass of binder $)$, and the relative concentration of silica to sodium oxide equivalent is reported as the silica modulus $m$. Saturated surface-dry (SSD) natural fine aggregate with fineness modulus of 2.42 and specific gravity of 2.65 was used for all mixtures. Crushed stone composed predominately of rose quartz with a nominal maximum particle size of $9.5 \mathrm{~mm}$, bulk density of $1560 \mathrm{~kg} / \mathrm{m}^{3}$, and specific gravity of 2.71 was used as coarse aggregate, and was used in SSD condition. Mixture proportions were selected based on preliminary investigations which indicated acceptable workability and appreciable compressive strength [55], and are detailed in Table 2. Alkali-activated FC and GGBFS mixtures included $0.1 \%$ dosage of rosin-based air-entraining agent for the purpose of workability improvement, as demonstrated elsewhere [55]. ASTM C150 Type I/II ordinary portland cement concrete (PCC) control mixtures were selected to produce similar compressive strengths as expected for the selected alkali-activated FC 
172

Table 1: Chemical Oxide Composition and Selected Physical Properties of Binders

and GGBFS mixtures.

\begin{tabular}{crr} 
& $\begin{array}{r}\text { GGBFS } \\
\text { \% by mass }\end{array}$ \\
\cline { 2 - 3 } & & FC \\
$\mathrm{SiO}_{2}$ & 36.0 & 37.7 \\
$\mathrm{Al}_{2} \mathrm{O}_{3}$ & 10.5 & 20.0 \\
$\mathrm{CaO}$ & 39.8 & 23.4 \\
$\mathrm{MgO}$ & 7.9 & 4.3 \\
$\mathrm{Na}_{2} \mathrm{O}$ & 0.3 & 1.7 \\
$\mathrm{SO}_{3}$ & 2.1 & 2.4 \\
$\mathrm{~K}_{2} \mathrm{O}_{2}$ & 0.2 & 0.6 \\
$\mathrm{Fe}_{2} \mathrm{O}_{3}$ & 0.7 & 5.6
\end{tabular}

\subsection{Specimen preparation}

24 cylindrical concrete specimens measuring $150 \mathrm{~mm}$ in length and $75 \mathrm{~mm}$ in diameter were cast in accordance with the specifications of ASTM C192 for each mixture proportion as listed in Table 2. The specimen size was limited to $75 \mathrm{~mm}$ due to the expense of the reagent-grade activators. Half of the specimens were cured at elevated temperature $\left(48 \pm 0.25\right.$ hours @ $\left.50 \pm 0.1^{\circ} \mathrm{C}\right)$ and the other half were cured at ambient temperature $\left(28 \pm 0.5\right.$ days @ $22 \pm 1^{\circ} \mathrm{C}$ and $>95 \% \mathrm{RH})$. All specimens remained sealed for the duration of curing to prevent moisture loss. After curing, specimens were de-molded and test faces were ground flat and plane using a wet silicon carbide grinding belt. 
Table 2: Mixture Proportions

\begin{tabular}{lrrrrrrrr} 
ID & $\begin{array}{r}\text { \% } \\
\text { (binder }\end{array}$ & $m$ & $\begin{array}{r}\% \mathrm{SiO}_{2} \\
\text { mass })\end{array}$ & $\begin{array}{r}\mathrm{s} / \mathrm{b} \\
(\mathrm{binder} \\
\text { mass })\end{array}$ & $\begin{array}{r}\text { Solution } \\
\left(\mathrm{kg} / \mathrm{m}^{3}\right)\end{array}$ & $\begin{array}{r}\text { Binder } \\
\left(\mathrm{kg} / \mathrm{m}^{3}\right)\end{array}$ & $\begin{array}{r}\text { Fine Aggr. } \\
\left(\mathrm{kg} / \mathrm{m}^{3}\right)\end{array}$ & $\begin{array}{r}\text { Coarse Aggr. } \\
\left(\mathrm{kg} / \mathrm{m}^{3}\right)\end{array}$ \\
\hline PCC1 & - & - & - & 0.40 & 228 & 570 & 658 & 780 \\
PCC2 & - & - & - & 0.36 & 228 & 620 & 610 & 780 \\
\hline FC1 & 4.0 & 1.5 & 6.0 & 0.40 & 228 & 570 & 658 & 780 \\
FC2 & 5.0 & 1.5 & 7.5 & 0.40 & 228 & 570 & 658 & 780 \\
FC3 & 6.0 & 1.5 & 9.0 & 0.40 & 228 & 570 & 658 & 780 \\
FC4 & 6.0 & 1.5 & 9.0 & 0.40 & 248 & 620 & 610 & 780 \\
\hline GGBFS1 & 4.0 & 0.75 & 3.0 & 0.40 & 228 & 570 & 658 & 780 \\
GGBFS2 & 5.0 & 0.75 & 3.75 & 0.40 & 228 & 570 & 658 & 780 \\
GGBFS3 & 6.0 & 0.75 & 4.0 & 0.40 & 228 & 570 & 658 & 780 \\
GGBFS4 & 5.0 & 0.75 & 3.75 & 0.40 & 248 & 620 & 610 & 780 \\
GGBFS5 & 2.0 & 1.5 & 5.0 & 0.40 & 228 & 570 & 658 & 780 \\
GGBFS6 & 2.5 & 1.5 & 6.25 & 0.40 & 228 & 570 & 658 & 780
\end{tabular}

\subsection{Test methods}

The compressive strength, splitting tensile strength, modulus of elasticity, Poisson's ratio, and stress-strain relationship were experimentally evaluated for each mixture at each curing condition, providing four replicates for each measurement. The average unit weight of each batch was recorded to an accuracy of $1 \mathrm{~kg} / \mathrm{m}^{3}$. Compressive strength was determined in accordance with the specifications of ASTM C39 using a stress application rate of 15 $\mathrm{MPa} / \mathrm{min}$. Splitting tensile strength, which is known to overestimate the tensile strength of concrete when compared to direct tension testing [38], was determined in accordance with the specifications of ASTM C496 using a stress application rate of about $1 \mathrm{MPa} / \mathrm{min}$. The width of the bearing strips for the splitting test was less than $8 \%$ of the cylinder diameter in order to achieve repeatable results, as Rocco et al. [56] showed significant 
variation in tests results when bearing strips exceeded this limit. The static chord modulus of elasticity and Poisson's ratio were determined in general agreement with the specifications of ASTM C469, except for that the testing was performed under closed-loop displacement control. This modification in test procedure was made in order to allow evaluation of the post-failure strain response. Specimens were loaded in pure uniaxial compression at a constant displacement rate of $0.1 \mathrm{~mm} / \mathrm{min}$ and were instrumented with an axial and radial extensometer, as shown in Figure 1. Post-failure strain measurements were also desired, and because failure typically causes the mounted gages to slip, two LVDT were also deployed in diametrically opposed positions in the axial direction.

\section{Results and Discussion}

The average compressive strength, tensile strength, elastic modulus, and Poisson's ratio for each mixture (4 replicates) are reported in Table 3. The unit weights of all concretes were within $2400 \pm 27 \mathrm{~kg} / \mathrm{m}^{3}$. Individual unit weights are not reported due to their similarity between mixtures.

\subsection{Compressive strength}

Ambient-temperature-cured $\left(28 \mathrm{~d} @ 22^{\circ} \mathrm{C}\right)$ activated fly ash concrete exhibits very low compressive strength compared to identical specimens cured at elevated temperature $\left(48 \mathrm{~h} @ 50^{\circ} \mathrm{C}\right)$. No such effect is observed in compressive strength results for alkali-activated GGBFS concrete, as has been reported by a few studies $[19,55]$. For both binders, increased binder content results in reduced compressive strength as indicated by the strength reduction between FC formulations $\mathrm{FC} 3$ and $\mathrm{FC} 4$ and GGBFS formulations 


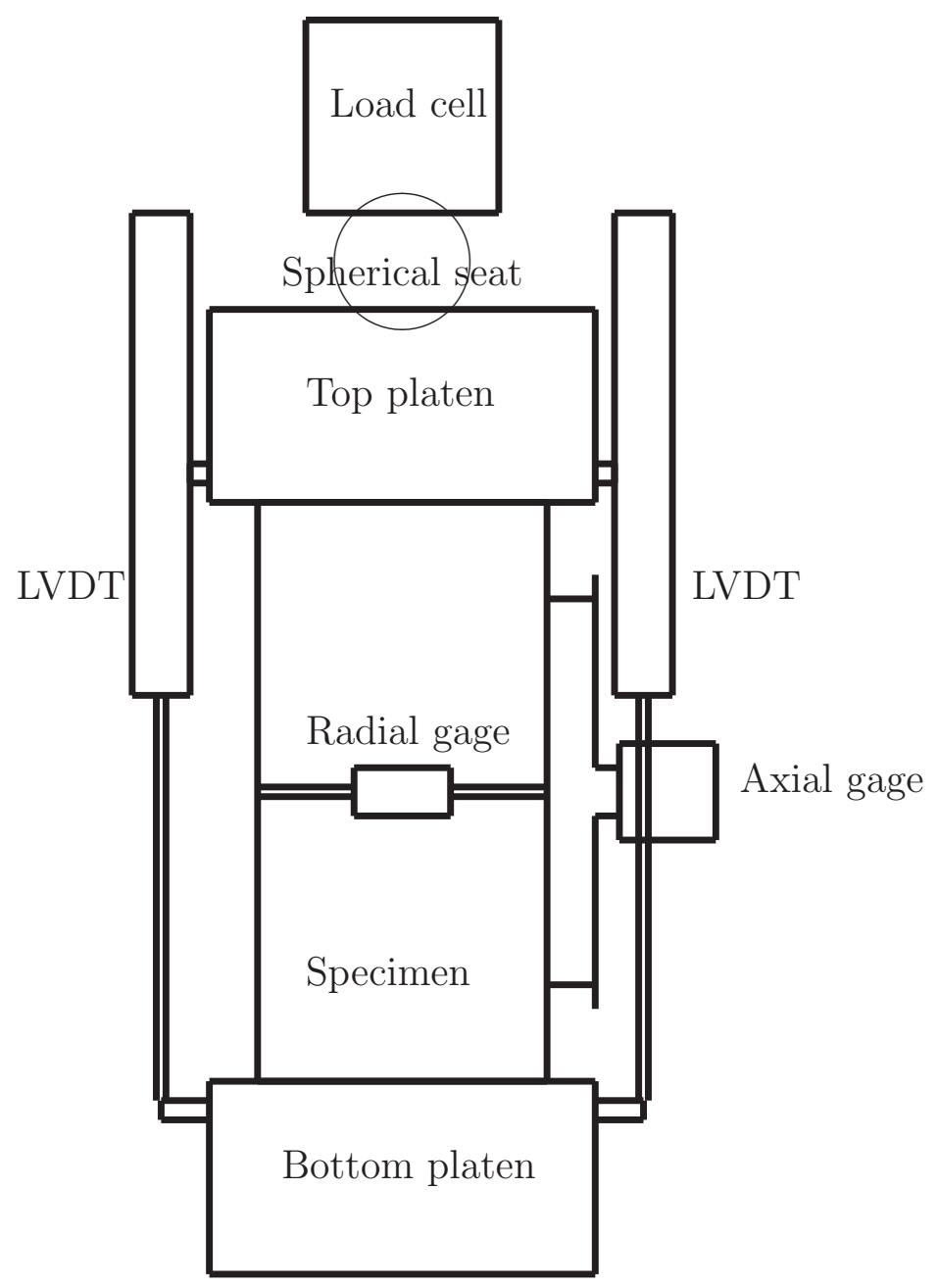

Figure 1: Test configuration for determination of modulus of elasticity, Poisson's ratio, and stress-strain relationship. 
Table 3: Summary of compressive strength $f_{c}^{\prime}$, tensile strength $f_{c t}$, elastic modulus $E$, and Poisson's ratio $\mu$ results for all mixtures.

\begin{tabular}{|c|c|c|c|c|c|}
\hline \multirow[t]{2}{*}{ ID } & Curing & $f_{c}^{\prime}$ & $f_{c t}$ & $E$ & \\
\hline & Condition & $\mathrm{MPa}$ & $\mathrm{MPa}$ & $\mathrm{GPa}$ & \\
\hline PCC1 & $28 \mathrm{~d} @ 22^{\circ} \mathrm{C}$ & 39.5 & 5.9 & 33.1 & 0.184 \\
\hline PCC2 & $28 \mathrm{~d} @ 22^{\circ} \mathrm{C}$ & 40.9 & 6.2 & 32.7 & 0.175 \\
\hline \multirow[t]{2}{*}{ FC1 } & $28 \mathrm{~d} @ 22^{\circ} \mathrm{C}$ & 16.2 & 2.9 & 17.7 & 0.126 \\
\hline & $48 \mathrm{~h} @ 50^{\circ} \mathrm{C}$ & 31.5 & 6.1 & 28.8 & 0.128 \\
\hline \multirow[t]{2}{*}{$\mathrm{FC} 2$} & $28 \mathrm{~d} @ 22^{\circ} \mathrm{C}$ & 28.9 & 6.7 & 21.5 & 0.128 \\
\hline & $48 \mathrm{~h} @ 50^{\circ} \mathrm{C}$ & 47.7 & 7.6 & 26.0 & 0.124 \\
\hline \multirow[t]{2}{*}{ FC3 } & $28 \mathrm{~d} @ 22^{\circ} \mathrm{C}$ & 22.9 & 3.8 & 22.6 & 0.127 \\
\hline & $48 \mathrm{~h} @ 50^{\circ} \mathrm{C}$ & 50.3 & 7.5 & 35.5 & 0.124 \\
\hline \multirow[t]{2}{*}{$\mathrm{FC} 4$} & $28 \mathrm{~d} @ 22^{\circ} \mathrm{C}$ & 21.3 & 4.1 & 10.5 & 0.127 \\
\hline & $48 \mathrm{~h} @ 50^{\circ} \mathrm{C}$ & 40.9 & 6.5 & 30.9 & 0.126 \\
\hline \multirow[t]{2}{*}{ GGBFS1 } & $28 \mathrm{~d} @ 22^{\circ} \mathrm{C}$ & 33.7 & 6.8 & 34.2 & 0.129 \\
\hline & $48 \mathrm{~h} @ 50^{\circ} \mathrm{C}$ & 29.5 & 6.1 & 31.7 & 0.125 \\
\hline \multirow[t]{2}{*}{ GGBFS2 } & $28 \mathrm{~d} @ 22^{\circ} \mathrm{C}$ & 44.7 & 7.2 & 26.2 & 0.130 \\
\hline & $48 \mathrm{~h} @ 50^{\circ} \mathrm{C}$ & 44.0 & 7.4 & 28.2 & 0.126 \\
\hline \multirow[t]{2}{*}{ GGBFS3 } & $28 \mathrm{~d} @ 22^{\circ} \mathrm{C}$ & 46.7 & 6.3 & 27.0 & 0.127 \\
\hline & $48 \mathrm{~h} @ 50^{\circ} \mathrm{C}$ & 45.6 & 7.7 & 25.4 & 0.124 \\
\hline \multirow[t]{2}{*}{ GGBFS4 } & $28 \mathrm{~d} @ 22^{\circ} \mathrm{C}$ & 35.0 & 6.3 & 27.9 & 0.134 \\
\hline & $48 \mathrm{~h} @ 50^{\circ} \mathrm{C}$ & 37.7 & 6.2 & 28.9 & 0.129 \\
\hline \multirow[t]{2}{*}{ GGBFS5 } & $28 \mathrm{~d} @ 22^{\circ} \mathrm{C}$ & 45.7 & 8.3 & 22.4 & 0.125 \\
\hline & $48 \mathrm{~h} @ 50^{\circ} \mathrm{C}$ & 48.7 & 7.4 & 22.9 & 0.128 \\
\hline \multirow[t]{2}{*}{ GGBFS6 } & $28 \mathrm{~d} @ 22^{\circ} \mathrm{C}$ & 52.6 & 8.4 & 33.5 & 0.127 \\
\hline & $48 \mathrm{~h} @ 50^{\circ} \mathrm{C}$ & 50.8 & 7.7 & 33.5 & 0.126 \\
\hline
\end{tabular}


GGBFS2 and GGBFS4. Improved strength with increased binder content has been observed in PCC [57]. The propensity of activated concrete for microcracking, particularly under elevated-temperature-curing, has been discussed by Collins and Sanjayan [58]. It is likely that this microcracking, combined with increased volume fraction of the paste phase, leads to the reduction in strength of alkali-activated concrete with increased binder content.

\subsection{Tensile strength}

The average tensile strength of PCC control specimens is $14.1 \pm 0.6 \%$ of the corresponding compressive strength, which is within the expected range of 10-15\%. The tensile strengths of alkali-activated FC and GGBFS concrete observed in this study is marginally higher than those of PCC control mixtures. The average splitting tensile strength of alkali-activated GGBFS concrete is $17.0 \pm 2.1 \%$ of the corresponding compressive strength, which is significantly higher than observed for PCC mixtures in a similar strength range. The sensitivity of the splitting tensile strength of activated fly ash concrete to the compressive strength appears to be affected by the curing condition; when cured at ambient temperature, the average splitting tensile strength is $19.4 \pm 2.8 \%$ of the corresponding compressive strength, while the ratio is $16.5 \pm 1.9 \%$ when cured at elevated temperature.

The splitting tensile strength and corresponding compressive strength of activated fly ash and GGBFS concrete are plotted in Fig. 2. Two prediction models are proposed which relate the splitting tensile strength to the compressive strength. The first, Equation 12, is of the general form of Equation 1 and fits the data quite well $\left(R^{2}=0.86\right)$. A second proposed equation is also given, following the common convention of limiting the power $B$ in Equation 
1 to $\frac{1}{2}$, as in [42-45]. This square-root model (Equation 13) fits the data reasonably well $\left(R^{2}=0.80\right)$, but not quite as well as with the unrestricted power (Equation 12). The goodness of fit of both proposed equations is considered quite acceptable due to the previously established variability of splitting tensile test results [56].

$$
\begin{gathered}
f_{c t}=\frac{2}{5}\left(f_{c}^{\prime}\right)^{\frac{7}{9}} \\
f_{c t}=1.08 \sqrt{f_{c}^{\prime}}
\end{gathered}
$$

In addition to the proposed models (Equations 12 and 13), several previously proposed models for splitting tensile strength of concrete are also included for comparison on Figure 2. These include the model proposed by Lee and Lee [44] for alkali-activated mixed fly ash/slag concrete, that proposed by Sofi et al. [45] for high-strength inorganic polymer concrete, the ACI 318 [42] model for normal strength PCC, and a model proposed by Carrasquilio and Nilson [43] for high strength PCC. The splitting tensile strengths observed here for alkali-activated FC and GGBFS concretes far exceed the predictions for both portland cement concrete [42, 43] and for alkali-activated and geopolymer concrete $[44,45]$ by a factor of nearly two. Lee and Lee [44] and Sofi et al. [45], despite using similar materials as used in the present study, used comparatively high solution-to-binder $(s / b)$ ratios; the former did not specifically specify $s / b$, but in most cases specified mass ratios of water to fly ash greater than 1 , and the latter used $s / b=0.56$. The comparatively low ratio used in the present study $(s / b=0.40)$ is a likely reason for the discrepancy. A few other studies have suggested improved 


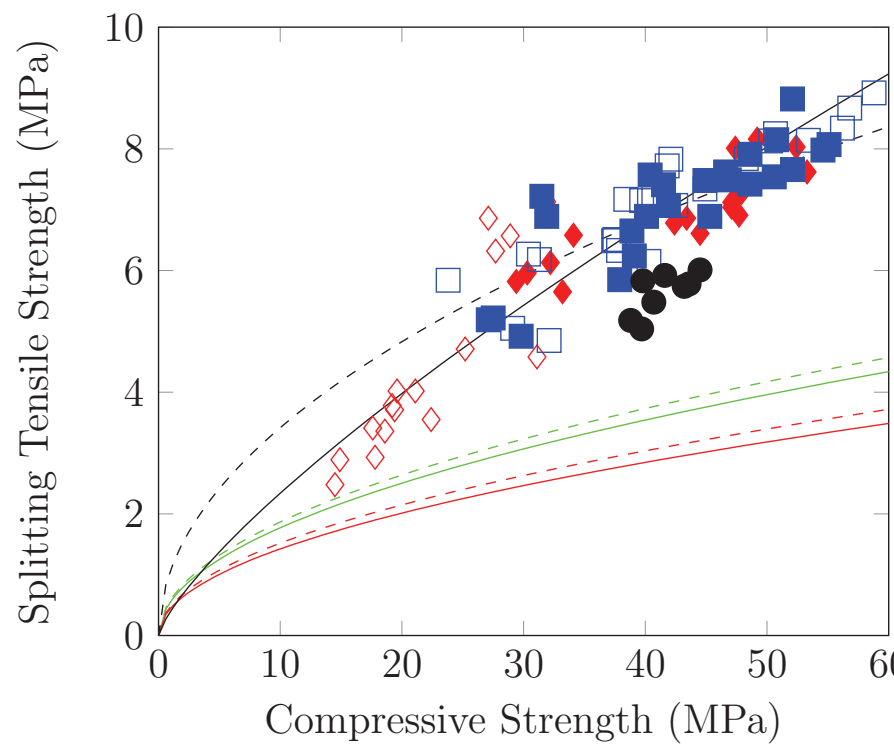

tensile strength in alkali-activated concretes compared to PCC [22, 52, 53], as is seen in the present study.

$\diamond \quad \mathrm{FC} 22^{\circ} \mathrm{C}$

- $\mathrm{FC} 50^{\circ} \mathrm{C}$

$\square$ GGBFS $22^{\circ} \mathrm{C}$

- GGBFS $50^{\circ} \mathrm{C}$

- PCC

- Eq. $2[42]$

- - Eq. $3[43]$

— Eq. 9 [44]

-.- Eq. 10 [45]

Eq. 12

-.- Eq. 13

Figure 2: Splitting tensile strength $f_{c t}$ and compressive strength $f_{c}^{\prime}$ of alkali activated FC and GGBFS concrete along with proposed models (Eq. 12 and 13) and existing models proposed by Lee and Lee [44], Sofi et al. [45], ACI 318 [42], and Carrasquilio and Nilson [43]

\subsection{Modulus of elasticity and Poisson's ratio}

The axial and lateral strain relationships in the elastic region under uniaxial compression for alkali-activated concrete are highly linear, as expected. Representative curves are presented in Figures 3 and 4 for activated fly ash and GGBFS concrete, respectively. Poisson's ratio for alkali-activated FC and GGBFS concrete mixtures is $0.127 \pm 0.003$, while PCC control specimens exhibited Poisson's ratio very near the expected value of 0.18 . This is a very 
surprising result which has gone unreported in the existing literature, and can be seen in Figures 3 and 4 where the lateral strain curve for PCC is very similar to those for alkali-activated FC and GGBFS concrete formulations even though the axial strain curve is much steeper. The modulus of elasticity of all alkali-activated FC and GGBFS concrete mixtures is within the expected range for concrete; observations are within $10 \leq E \leq 35 \mathrm{GPa}$. The individual values observed for the modulus of elasticity of activated fly ash and GGBFS concrete are plotted against the corresponding compressive strengths in Figures 5 and 6.

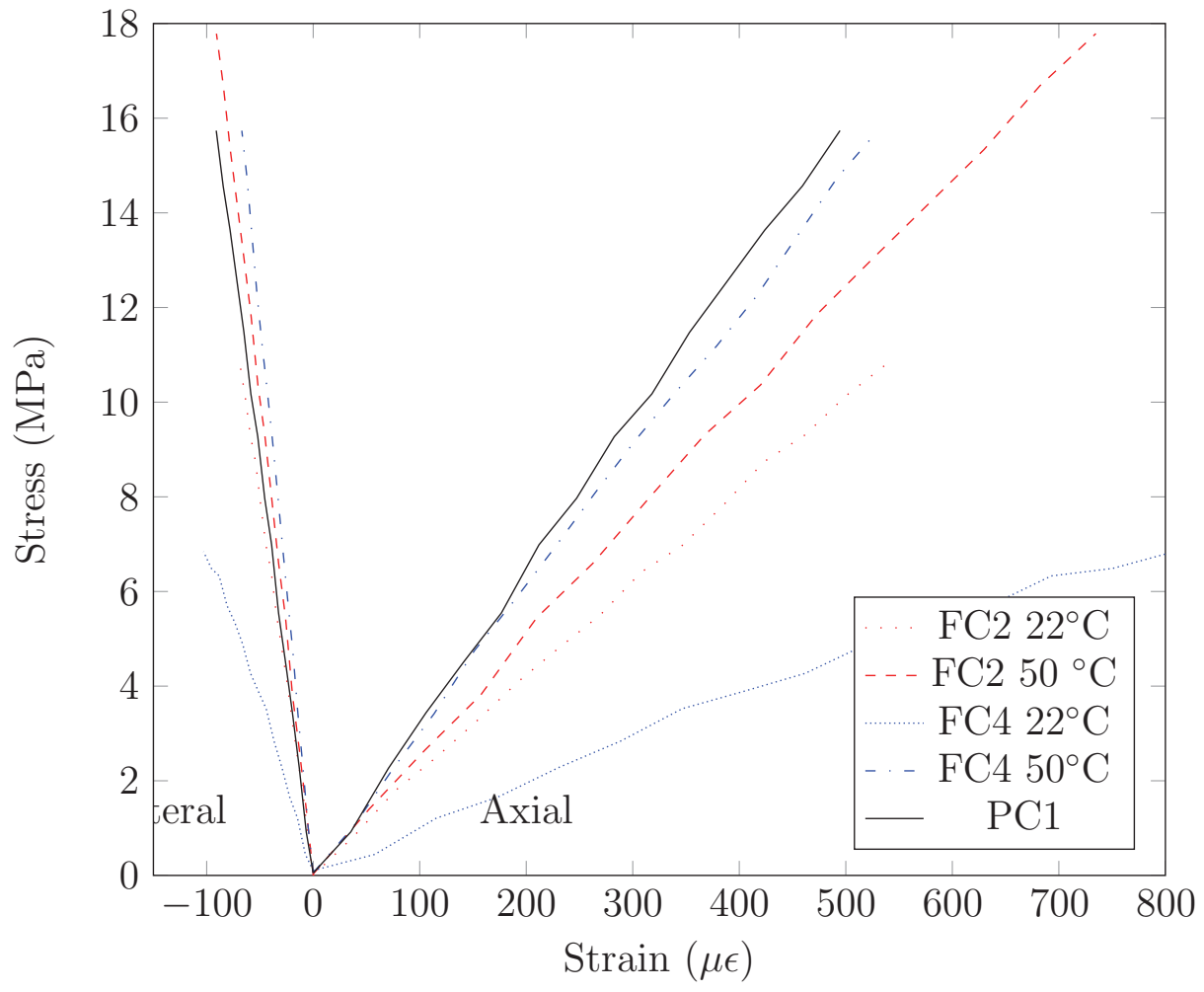

Figure 3: Axial and lateral stress-strain relationships for alkali-activated fly ash concrete in pure uniaxial compression within the proportional limit. 


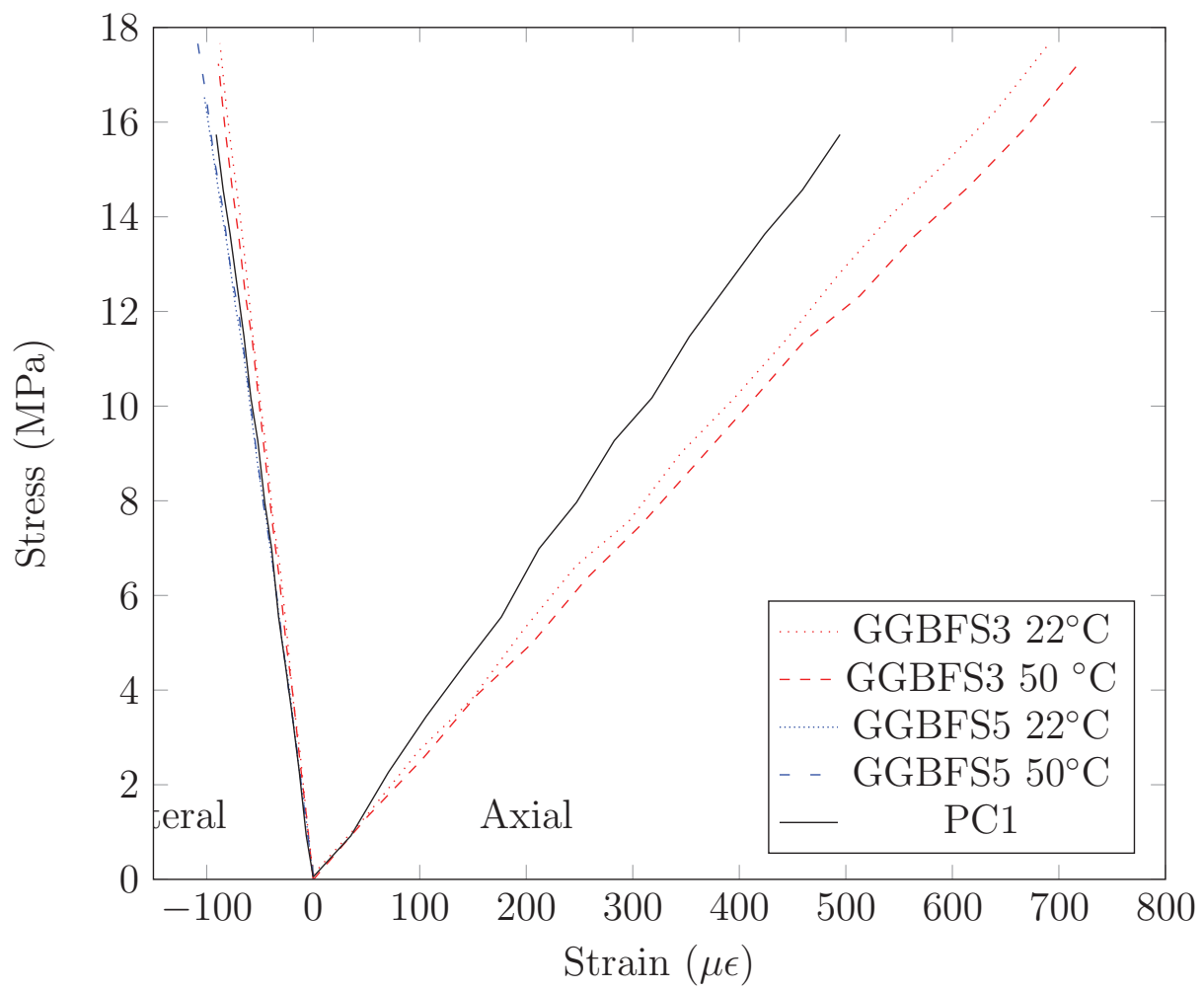

Figure 4: Axial and lateral stress-strain relationships for alkali-activated GGBFS concrete in pure uniaxial compression within the proportional limit.

The modulus of elasticity of activated fly ash concrete appears to vary directly with the compressive strength, and this variation shows no discernible difference from that of PCC, as modeled by equation 5. Two models are proposed: the first, given by equation 14 , is of the form of equation 1 ; the second, given by equation 15 , is of the same form with the constraint that the power $B=\frac{1}{2}$, as in equation 5 . The modulus of elasticity $E$ and compressive strength $f_{c}^{\prime}$ are of course in MPa. The fitted equations vary only slightly from the ACI 318 equation (equation 5 in terms of both predicted 
values and goodness of fit. Coefficients of determination $\left(R^{2}\right)$ for equations 5,14 , and 15 are $0.54,0.58$, and 0.60 , respectively. Despite these low coefficients of correlation which occur as a result of highly variable data and several potential outliers, all three equations do indeed provide a good representation of the trend. Additionally, because of the significant variation in the data, it is really impossible to conclude that one of these equations is a better predictor than another without additional studies. The model proposed by Lee and Lee [44] for alkali-activated fly ash/GGBFS mixtures is also plotted; this model drastically underestimates the modulus of elasticity of the alkali-activated FC mixtures tested here, which could again be due to the higher water content of those mixtures, or purely due to the use of mixed fly ash/GGBFS formulations. Additional models fit using curing condition as an additional predictor for the modulus of elasticity of activated fly ash concrete only marginally improve the goodness of fit. However, since the curing condition has been established as a significant effect in the compressive strength, it is likely that its use as a parameter in determining the modulus of elasticity represents the addition of a confounding variable. Furthermore, it should be noted that because mixture proportions in Table 2 are by weight and because the specific gravities of the binders are not the same, the volume fraction of aggregate is not constant between PCC and alkali-activated FC or GGBFS binders (ranging from 0.279 to 0.305 ). The aggregate volume fraction, as discussed by Hansen [59] is one of the main factors affecting the modulus of elasticity of concrete, although theoretically, the effect of such a 
slight change in aggregate volume is fairly small.

$$
\begin{aligned}
& E=2900\left(f_{c}^{\prime}\right)^{\frac{3}{5}} \\
& E=4400\left(f_{c}^{\prime}\right)^{\frac{1}{2}}
\end{aligned}
$$

The modulus of elasticity of activated GGBFS concrete, averages about $30 \mathrm{GPa}$, does not appear to vary with compressive strength over the range $20 \mathrm{MPa} \leq f_{c}^{\prime} \leq 60 \mathrm{MPa}$, as shown in Figure 6, nor is any significant variation with curing condition observed. Attempting to fit a linear model to these data results in a negative coefficient of determination $\left(R^{2}<0\right)$. The practical meaning of this is that a constant relationship (horizontal line) fits these data better than the least-squares linear regression equation. Additionally, the ACI 318 equation (equation 5) fits the data poorly. This is reminiscent of the conclusions drawn by Duxson et al. [54] regarding the modulus of elasticity of geopolymer concretes made with natural pozzolan binders, where it was suggested that the microstructure, composition, and degree of hydration had a more significant effect on the modulus of elasticity than the compressive strength or solution parameters. This is due to the fact that the activator and curing condition affect the composition, density, volume fraction, and physical size of the product phases within the binder [19, 26], which can have significant effects on the mechanical properties. This result could also be a result of the significant microcracking that has been demonstrated in sodium silicate-activated GGBFS concrete [58], which may be increasingly prevalent as compressive strength increases. No significant correlation was found between the modulus of elasticity of activated GGBFS concrete and 

$m$, or silica content $\left.m \cdot \mathrm{Na}_{2} \mathrm{O}\right)$.

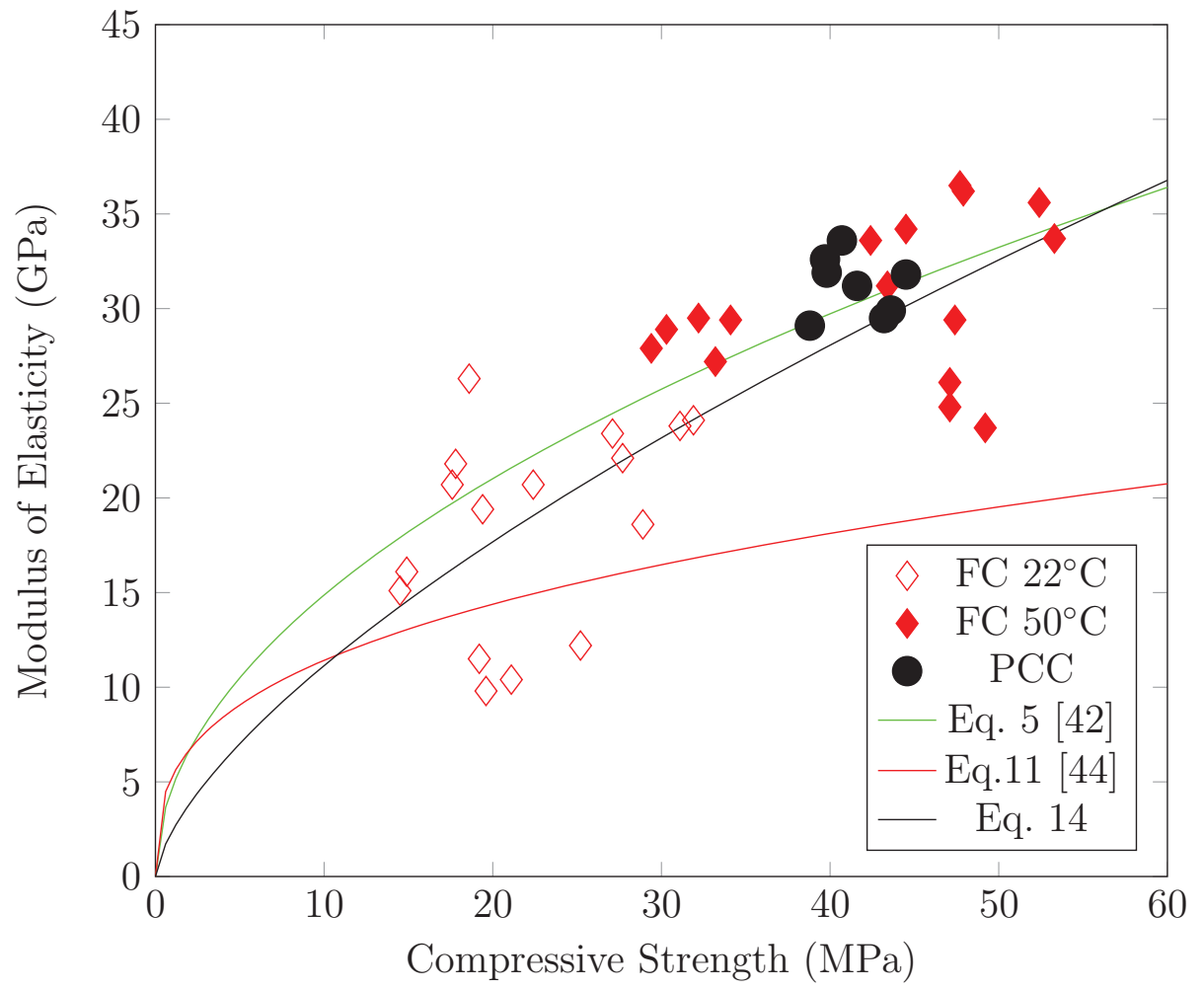

Figure 5: Modulus of elasticity and compressive strength of alkali-activated fly ash concrete.

the activator concentrations (sodium oxide content $\% \mathrm{Na}_{2} \mathrm{O}$, silica modulus

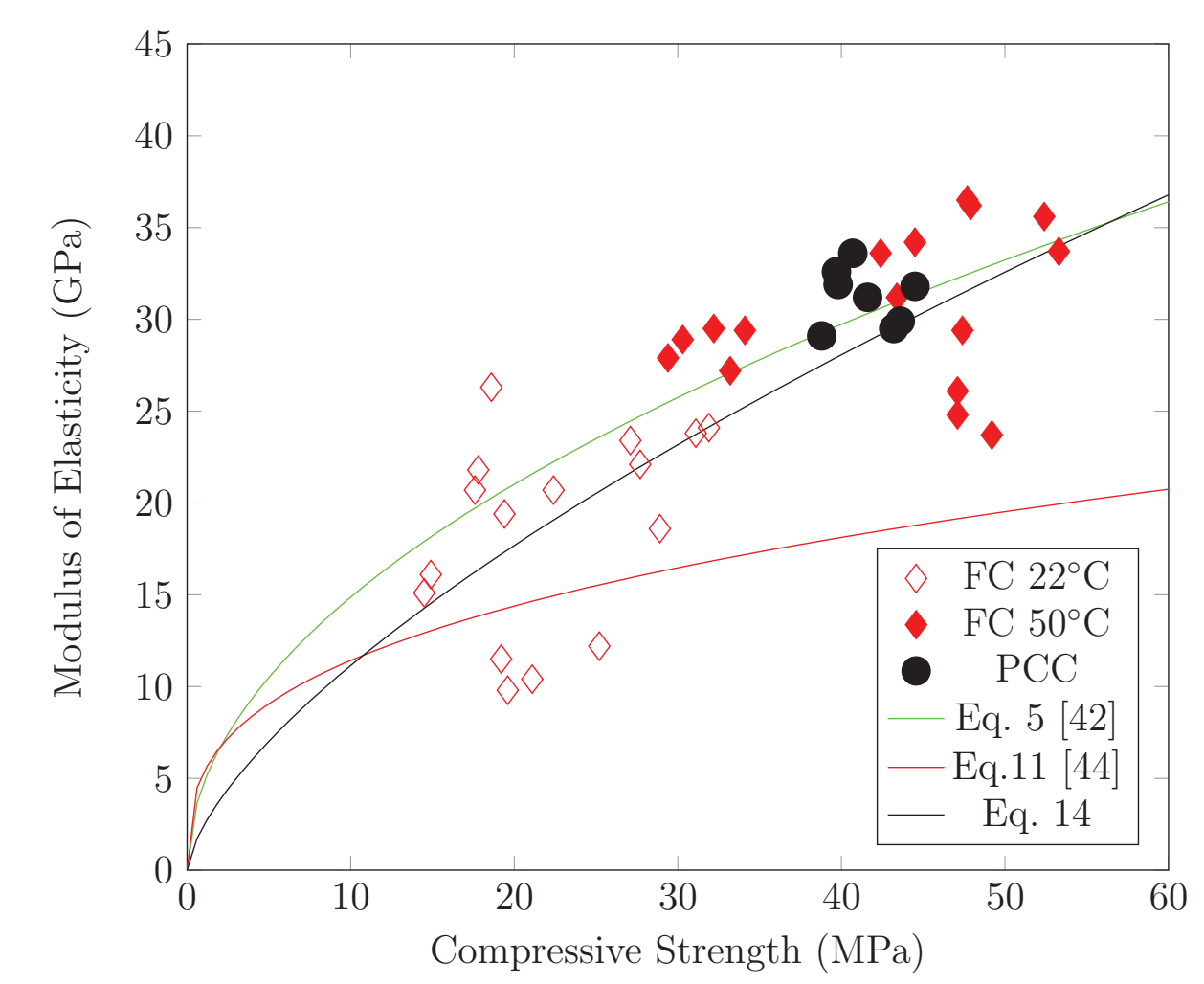

\subsection{Stress-strain relationships}

A few representative stress-strain curves are shown for alkali-activated FC and GGBFS concrete in Figures 7 and 8. These experimental curves are compared with the numerically-derived curves for PCC after Popovics [48] (Equation 6). The stress-strain curves for alkali-activated FC concrete resemble the numerical estimates for PCC fairly closely. Minor differences in 


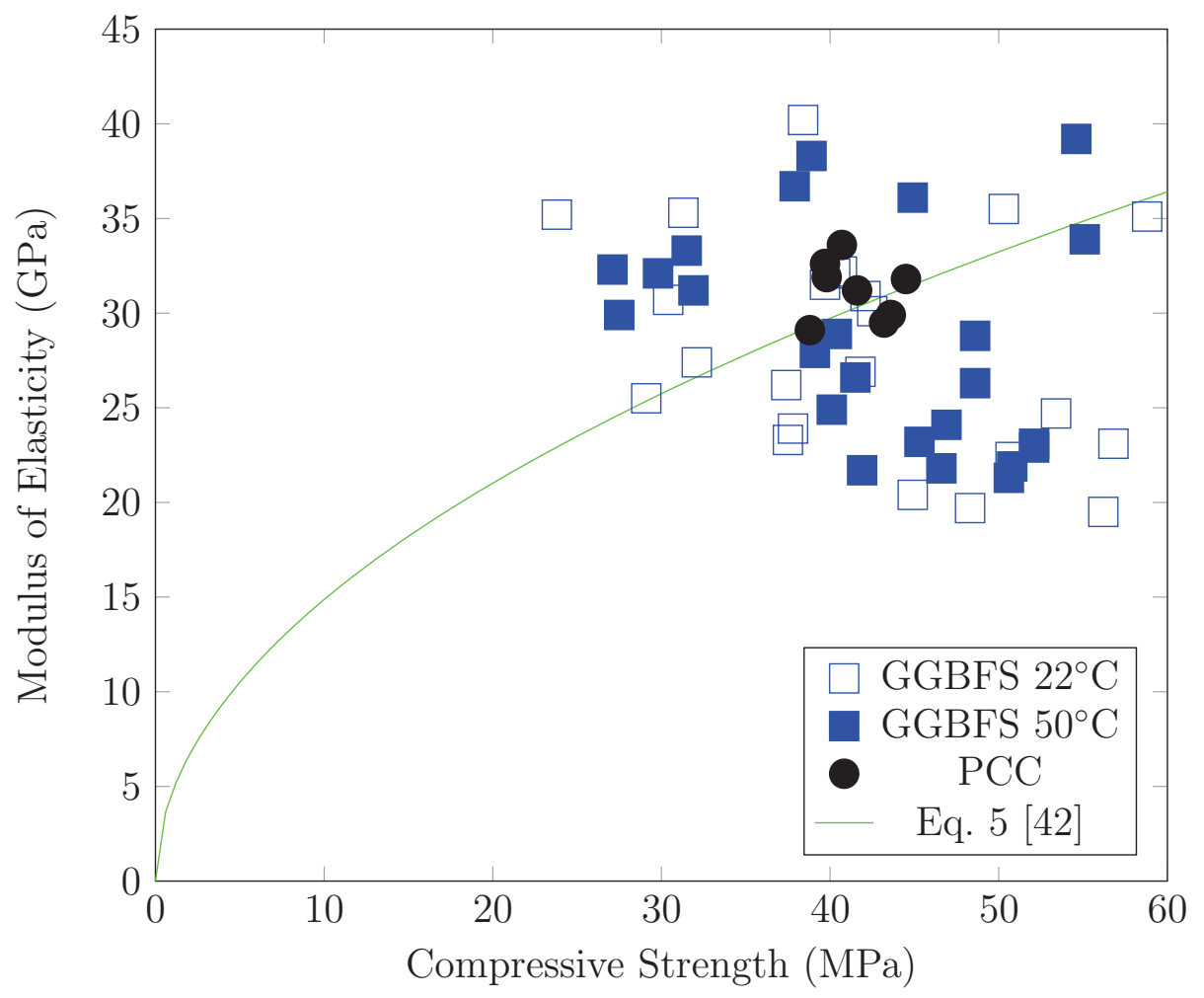

Figure 6: Modulus of elasticity and compressive strength of alkali-activated GGBFS concrete. 
the strain corresponding to the ultimate stress are observed under elevatedtemperature curing, and the behavior is slightly more brittle. Additionally, alkali-activated FC concrete shows a more rapid decline in stress during postpeak strain softening. This suggests decreased toughness as compared to PCC. Overall, however, the stress-strain behavior of alkali-activated FC concrete is not much different than that typical of PCC. On the other hand, the stress-strain behavior of alkali-activated GGBFS concrete is starkly different than that of PCC. The strain corresponding to the ultimate stress is quite similar, but the post-peak behavior is drastically dissimilar. Where PCC displays gradual strain softening beyond the ultimate stress, alkaliactivated GGBFS displays brittle fracture immediately following the peak. This increased brittleness has been bserved by previous studies [53], and has generally been attributed to the high prevalence of microcracking in alkali-activated GGBFS [58]. Due to the limited number of test specimens evaluated here, no attempt is made to develop a numerical model of the stress-strain curve for alkali-activated FC and GGBFS concrete; some researchers have done so for PCC, but have generally used a very high sample size. For the purpose of this investigation, it is sufficient to conclude that the stress-strain behavior of alkali-activated fly ash concrete is similar to that of PCC, but that of alkali-activated GGBFS concrete exhibits high brittleness that is uncharacteristic of PCC.

\section{Summary of Conclusions}

The splitting tensile strength, modulus of elasticity, Poisson's ratio, and stress-strain relationships for alkali-activated FC and GGBFS concrete were 


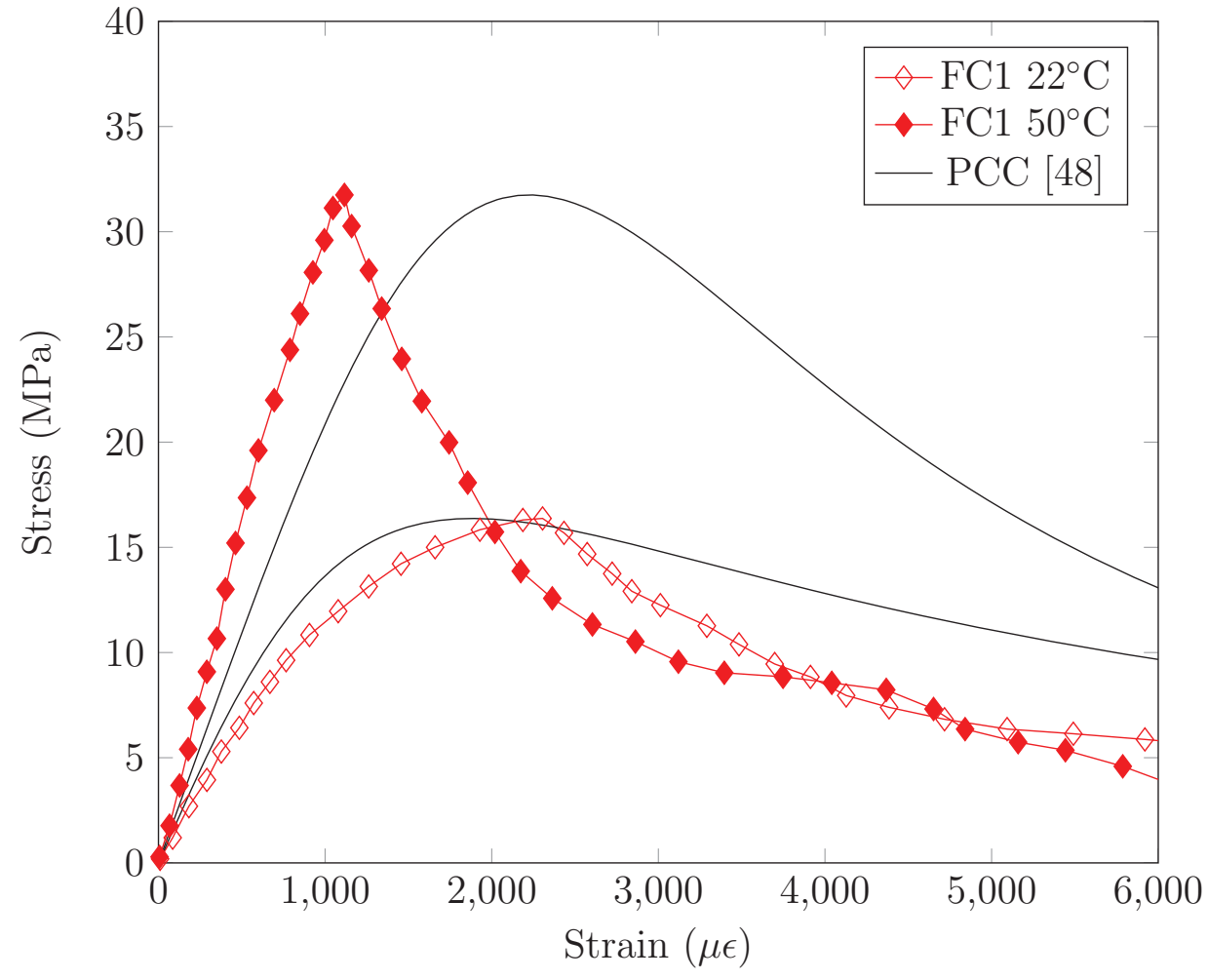

Figure 7: Representative stress-strain curves for alkali-activated fly ash concrete. Models for PCC after Popovics [48] are based on ultimate strength of given alkali-activated FC specimens 


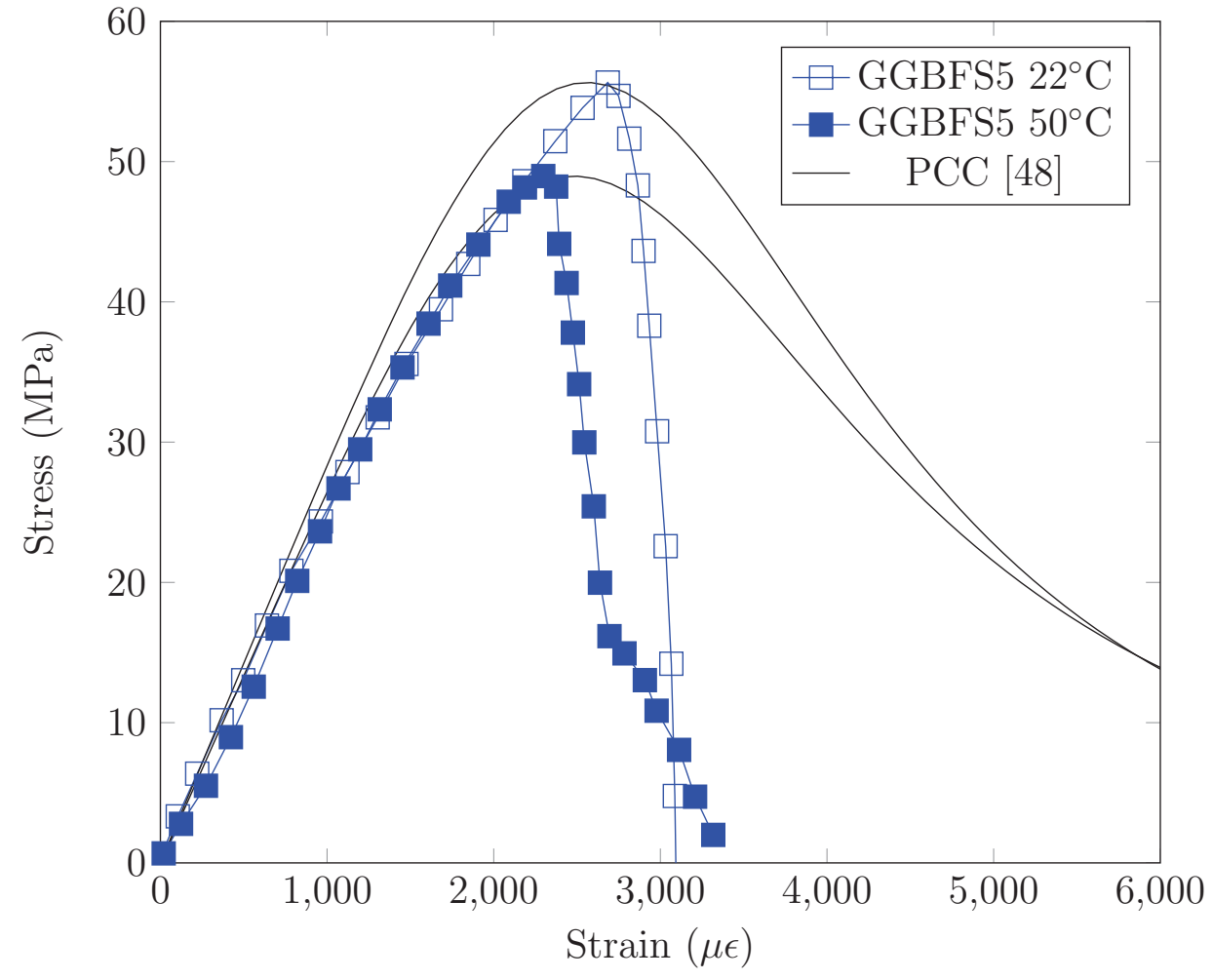

Figure 8: Representative stress-strain curves for alkali-activated GGBFS concrete. Models for PCC after Popovics [48] are based on ultimate strength of given alkali-activated GGBFS specimens 
studied experimentally. The following conclusions are drawn from the results of this study:

- The mechanical strength of alkali-activated fly ash concrete shows a significant effect from curing condition; ambient-temperature-curing $\left(28 \mathrm{~d} @ 22^{\circ} \mathrm{C}\right)$ resulted in significantly lower mechanical strength than elevated-temperature-curing $\left(48 \mathrm{~h} @ 50^{\circ} \mathrm{C}\right)$. In alkali-activated GGBFS concrete, the two curing conditions resulted in no difference in mechanical strength.

- The tensile strength of alkali-activated fly ash and GGBFS concrete is significantly higher than that of portland cement concrete with similar compressive strength.

- The splitting tensile strength of alkali-activated concrete is related to the corresponding compressive strength by a power function of similar form to those previously proposed for portland cement concrete. A relationship with $86 \%$ correlation is proposed relating the tensile and compressive strengths of alkali-activated FC and GGBFS concrete.

- Poisson's ratio for alkali-activated fly ash and slag concrete is about two-thirds that typical of portland cement concrete with excellent repeatability.

- Young's modulus of elasticity varies linearly with compressive strength for alkali-activated fly ash concrete, while the modulus remains relatively constant for activated GGBFS concrete over the entire range of compressive strengths represented in this study. Existing equations, 
viz., equations 4 and 5 (ACI 318), fit reasonably well despite wide variation in the data.

- Alkali-activated class-C fly ash concrete exhibits similar stress-strain behavior to ordinary portland cement concrete, marked by imperfect linear elasticity to failure followed by post-peak strain softening. Conversely, alkali-activated GGBFS concrete exhibits highly brittle behavior marked by near perfect linear elasticity followed by sudden and total failure.

\section{Acknowledgment}

The authors gratefully acknowledge the financial support of the University Transportation Research Center, Region 2 (UTRC2) and of the National Science Foundation through CAREER Grant Award No. 1055641.

\section{References}

\section{References}

[1] SM Jasinski. Mineral commodity summaries, cement, 2009.

[2] NA Madlool, R Saidur, MS Hossain, and NA Rahim. A critical review on energy use and savings in the cement industries. Renew Sust Energ Rev, 15(4):2042-2060, 2011.

[3] E Worrell, N Martin, and L Price. Potentials for energy efficiency improvement in the us cement industry. Energy, 25(12):1189-1214, 2000. 
[4] E Worrell, L Price, N Martin, C Hendriks, and LO Meida. Carbon dioxide emissions from the global cement industry 1. Annu Rev Energ Env, 26(1):303-329, 2001.

[5] S Khurana, R Banerjee, and U Gaitonde. Energy balance and cogeneration for a cement plant. Appl Therm Eng, 22(5):485-494, 2002.

[6] WT Choate. Energy and emission reduction opportunities for the cement industry. In Energy and emission reduction opportunities for the cement industry. BCS, Incorporated, 2003.

[7] ACI Committee 232. Use of fly ash in concrete (ACI 232.2R-03). American Concrete Institute, 2003.

[8] ACI Committee 232. Slag cement in concrete and mortar (ACI 233R03). American Concrete Institute, 2003 (Reapproved 2011).

[9] J Geiseler, H Kollo, and E Lang. Influence of blast furnace cements on durability of concrete structures. ACI Mater J, 92(3), 1995.

[10] N Bouzoubaa, MH Zhang, VM Malhotra, and DM Golden. Blended fly ash cements a review. ACI Mater J, 96(6), 1999.

[11] A Bilodeau and VM Malhotra. High-volume fly ash system: concrete solution for sustainable development. ACI Mater J, 97(1), 2000.

[12] VM Malhotra. High-performance high-volume fly ash concrete. Concr Int, 24(7), 2002. 
[13] LK Turner and FG Collins. Carbon dioxide equivalent (coj subi $2 \mathrm{i} / \mathrm{sub}_{\mathrm{i}-}$ e) emissions: A comparison between geopolymer and opc cement concrete. Constr Build Mat, 43:125-130, 2013.

[14] E Douglas, A Bilodeau, and VM Malhotra. Properties and durability of alkali-activated slag concrete. ACI Mater J, 89(5), 1992.

[15] AM Fernández-Jiménez, JG Palomo, and F Puertas. Alkali-activated slag mortars: mechanical strength behaviour. Cem Concr Res, 29(8): 1313-1321, 1999.

[16] A Palomo, MW Grutzeck, and MT Blanco. Alkali-activated fly ashes: a cement for the future. Cem Concr Res, 29(8):1323-1329, 1999.

[17] D Hardjito, SE Wallah, DMJ Sumajouw, and BV Rangan. On the development of fly ash-based geopolymer concrete. ACI Mater J, 101 (6), 2004.

[18] AM Fernández-Jiménez, A Palomo, and C Lopez-Hombrados. Engineering properties of alkali-activated fly ash concrete. ACI Mater J, 103(2), 2006.

[19] E Deir, BS Gebregziabiher, and S Peethamparan. Influence of starting material on the early age hydration kinetics, microstructure and composition of binding gel in alkali activated binder systems. Cem Concr Compos, 48:108-117, 2014.

[20] E Douglas, A Bilodeau, J Brandstetr, and VM Malhotra. Alkali activated ground granulated blast-furnace slag concrete: preliminary investigation. Cem Concr Res, 21(1):101-108, 1991. 
[21] SD Wang, KL Scrivener, and PL Pratt. Factors affecting the strength of alkali-activated slag. Cem Concr Res, 24(6):1033-1043, 1994.

[22] FG Collins and JG Sanjayan. Workability and mechanical properties of alkali activated slag concrete. Cem Concr Res, 29(3):455-458, 1999.

[23] T Bakharev, JG Sanjayan, and YB Cheng. Effect of elevated temperature curing on properties of alkali-activated slag concrete. Cem Concr Res, 29(10):1619-1625, 1999.

[24] A Palomo, MW Grutzeck, and MT Blanco. Alkali-activated fly ashes: a cement for the future. Cem Concr Res, 29(8):1323-1329, 1999.

[25] AM Fernandez-Jimenez, A Palomo, and C Lopez-Hombrados. Engineering properties of alkali-activated fly ash concrete. ACI Mater J, 103(2), 2006.

[26] BS Gebregziabiher, RJ Thomas, and S Peethamparan. Very early-age reaction kinetics and microstructural development in alkali-activated slag. Cem Concr Compos, 55(1):91-102, 2015.

[27] K Byfors, G Klingstedt, V Lehtonen, H Pyy, and L Romben. Durability of concrete made with alkali-activated slag. ACI Special Publication, $114,1989$.

[28] D Ravikumar and N Neithalath. Electrically induced chloride ion transport in alkali activated slag concretes and the influence of microstructure. Cem Concr Res, 47:31-42, 2013. 
[29] T Bakharev, JG Sanjayan, and YB Cheng. Resistance of alkali-activated slag concrete to acid attack. Cem Concr Res, 33(10):1607 - 1611, 2003.

[30] AM Fernández-Jiménez, I Garcia-Lodeiro, and A Palomo. Durability of alkali-activated fly ash cementitious materials. J Mater Sci, 42(9): 3055-3065, 2007.

[31] MAM Ariffin, MAR Bhutta, MW Hussin, M Mohd Tahir, and N Aziah. Sulfuric acid resistance of blended ash geopolymer concrete. Constr Build Mater, 43:80-86, 2013.

[32] S Donatello, A Palomo, and AM Fernández-Jiménez. Durability of very high volume fly ash cement pastes and mortars in aggressive solutions. Cem Concr Compos, 2013.

[33] PM Gifford and JE Gillott. Alkali-silica reaction (asr) and alkalicarbonate reaction (acr) in activated blast furnace slag cement (abfsc) concrete. Cem Concr Res, 26(1):21-26, 1996.

[34] AM Fernández-Jiménez and F Puertas. The alkali-silica reaction in alkali-activated granulated slag mortars with reactive aggregate. Cem Concr Res, 32(7):1019-1024, 2002.

[35] I García-Lodeiro, A Palomo, and AM Fernández-Jiménez. Alkaliaggregate reaction in activated fly ash systems. Cem Concr Res, 37 (2):175-183, 2007.

[36] T Akazawa. Tension test method for concrete. RILEM Bulletin, 16, 1953. 
[37] NJ Carino and HS Lew. Re-examination of the relation between splitting tensile and compressive strength of normal weight concrete. In $A C I J$ Proc, volume 79. ACI, 1982.

[38] JM Raphael. Tensile strength of concrete. In ACI J Proc, volume 81. ACI, 1984.

[39] SH Ahmad and SP Shah. Structural properties of high-strength concrete and its implications for precast concrete. PCI Journal, 30(6):92-119, 1985.

[40] FA Oluokun, EG Burdette, and JH Deatherage. Splitting tensile strength and compressive strength relationships at early ages. ACI Mater J, 88(2), 1991.

[41] F Oluokun. Prediction of concrete tensile strength from its compressive strength: an evaluation of existing relations for normal weight concrete. ACI Mater J, 88(3), 1991.

[42] ACI Committee 318. Building code requirements for structural concrete (ACI 318-08) and commentary (ACI 318R-08). American Concrete Institute, 2005.

[43] RL Carrasquilio and AH Nilson. Properties of high strength concrete subject to short-term loads. In ACI J Proc, volume 78. ACI, 1981.

[44] NK Lee and HK Lee. Setting and mechanical properties of alkaliactivated fly ash/slag concrete manufactured at room temperature. Construction and Building Materials, 47:1201-1209, 2013. 
[45] M Sofi, JSJ Van Deventer, PA Mendis, and GC Lukey. Engineering properties of inorganic polymer concretes (ipcs). Cement and Concrete Research, 37(2):251-257, 2007.

[46] A Pauw. Static modulus of elasticity of concrete as affected by density. $57(12), 1960$.

[47] TC Hsu, FO Slate, GM Sturman, and G Winter. Microcracking of plain concrete and the shape of the stress-strain curve. In ACI J Proc, volume 60. ACI, 1963.

[48] S Popovics. A numerical approach to the complete stress-strain curve of concrete. Cem Concr Res, 3(5):583-599, 1973.

[49] P Desayi and S Krishnan. Equation for the stress-strain curve of concrete. In ACI J Proc, volume 61. ACI, 1964.

[50] PT Wang, SP Shah, and AE Naaman. Stress-strain curves of normal and lightweight concrete in compression. In ACI J Proc, volume 75. ACI, 1978.

[51] DJ Carreira and KH Chu. Stress-strain relationship for plain concrete in compression. In ACI J Proc, volume 82. ACI, 1985.

[52] F Collins and JG Sanjayan. Cracking tendency of alkali-activated slag concrete subjected to restrained shrinkage. Cem Concr Res, 30(5):791$798,2000$.

[53] C Duran Atiş, C Bilim, Ö Çelik, and O Karahan. Influence of activator 
on the strength and drying shrinkage of alkali-activated slag mortar. Constr Build Mat, 23(1):548-555, 2009.

[54] P Duxson, JL Provis, GC Lukey, SW Mallicoat, WM Kriven, and JSJ Van Deventer. Understanding the relationship between geopolymer composition, microstructure and mechanical properties. Colloids and Surfaces A: Physicochemical and Engineering Aspects, 269(1):47-58, 2005.

[55] RJ Thomas, A Howe, and S Peethamparan. Alkali-activated cement free concrete: Development of practical mixtures for construction. Proceedings of the Transportation Research Board 93rd Annual Meeting, 2014.

[56] C Rocco, GV Guinea, J Planas, and M Elices. Size effect and boundary conditions in the brazilian test: experimental verification. Mater Struct, $32(3): 210-217,1999$.

[57] PK Mehta and PJM Monteiro. Concrete: microstructure, properties, and materials, volume 3. McGraw-Hill New York, 2006.

[58] F Collins and JG Sanjayan. Microcracking and strength development of alkali activated slag concrete. Cem Concr Compos, 23(4):345-352, 2001.

[59] TC Hansen. Influence of aggregate and voids on modulus of elasticity of concrete, cement mortar, and cement paste. In ACI Journal Proceedings, volume 62. ACI, 1965. 